\title{
Driving Performance through Strategic and Financial Planning (The Nigerian Experience)
}

\author{
Josephine C. Ene ${ }^{1}$,Emeka E. Ene ${ }^{2}$, \&Ioraver N. Tsegba ${ }^{3}$ \\ ${ }^{1}$ Department of Business Administration, Bingham University, Karu, Nassarawa State, Nigeria. \\ ${ }^{2}$ Entrepreneurship Development Center, Bingham University, Karu, Nassarawa State, Nigeria. \\ ${ }^{3}$ Department of Accounting \& Finance, Federal University of Agriculture, Makurdi-Nigeria.
}

\begin{abstract}
Effective performance management has been acknowledged by management scientists as sine qua non for optimal growth and development of organizations, for profit or not for profit making entities alike. Selected literatures reveal that hitherto, financial performance has been the primary focus of performance management in both private businesses and governmental ministries and agencies. However, recent arguments have revealed the flaws of the traditional performance management instruments and advocated contemporarily and more plausible instruments that could engender optimal growth and development of organizations. The primary objective of this paper is to review the performance management practices in Nigeria with a view to exploring contemporary and more pragmatic practices that would enhance service delivery by the government. The paper reveals, from existing literature, that public service in Nigeria is characterized by attendant weaknesses that engender poor performance in service delivery. It was also discovered that the performance management instrument in Nigeria public service is primarily focused on financial performances such as budget performance and, recently, value for money audit,and employee performance evaluation; with total neglect of other contributory ingredients of optimal service delivery. It was recommended that Nigerian government should tactically develop its performance management instruments along the morerobust balanced scorecard postulates; this will provide an all-inclusive basis for performance management and facilitate optimal performance in Nigeria public service.
\end{abstract}

Keywords:Performance Management, Financial Performance, Optimal Performance, Balanced Score Card, Public Service, Nigeria.

\section{Introduction}

Nigeria Public Service, with teeming civil servants in ministries, departments and agencies, is the largest and most complex enterprise in Nigeria. Federal public servants work in diverse areas to develop policies, provide advice to government and deliver services and programs directly to Nigerians. The nonpartisan and competent Federal Public Service contributes to the future of Nigeria; no other organization is so engaged in so many areas of Nigerian life. Public servants are committed and proud to serve their fellow Nigerians.

The world in which the federal Public Service operates has become more complex and in many ways more unpredictable over the last 15 years, especially after the trajectory of the global meltdown through early 2000. This new environment is characterized by a globalized economic landscape and ever-changing information and communications technologies. Governments, world over,are facing a daunting paradox. On one hand, they operate in an increasingly complex environment and must deliver on an expanded set of policy objectives in a world characterized by macroeconomic uncertainty, rapid social changes, technological innovations and rising citizens' expectations of what government ought to deliver. On the other hand, governments are hampered by unsustainable debt burdens and shrinking budgets. The ratio of general government debt to gross domestic product is high. Meanwhile, public trust in government is waning. Against this backdrop, not only must governments do more with less; they must do so in highly visible ways, if they are to regain the faith of the citizens.

As a key sector for the advancements needed in the socio-economic emancipation, the public sector has increasingly gained the attention of various developmental strategies especially in developing countries. The role of the state and its institutions is to partner with the private sector in carrying out the developmental agenda. Indeed the public sector has been under scrutiny to adopt the approaches of the private sector towards growth and development in all sectors of the economy, which has occasioned public private partnership (PPP) as a common strategy in running government developmental projects.

The drive for reforms in the public sector worldwide has focused attention on the measurement of performance in public sector organizations. 'Value for money' has become an important aspect of public sector management and is one of the factors that have stimulated the spread of performance measurement systems in governance (Palmer, 1993). Greater expectations of all levels of government, with increased accountability to 
stakeholders and requirements for increased efficiency and effectiveness in government operations, have also increased the focus on performance measurement (Hood, 1995). Indeed, performance measurement and program evaluation have been central to drives for a more efficient, effective and accountable public sector (Guthrie and English, 1997).

Governments need a better means of determining performance in relation to objectives (Atkinson and McCrindell, 1997). Performance measures have become too bountiful and too operationally focused (Atkinson and McCrindell, 1997; MAV, 1993). The result is performance measures that are overwhelming and do not always meet the needs of relevant stakeholders. Performance measurement in government is related to accountability (Broadbent, 1995; Sinclair, 1995; Guthrie and English, 1997), and inadequate performance measurement systems do not help in understanding what services are provided and to whom.

The overarching objective of this paper titled "Driving Performance through Strategic and Financial Planning"is to review the performance managementpractices in Nigeria with a view to exploring contemporary and more pragmatic practices that would enhance service delivery by the government.

The rest of the paper is presented in the following order: first challenges of Nigerian public service and efforts of Nigerian government towards achieving effectiveness in service delivery is distilled from related literatures; after which a conceptual framework of the subject matter is presented; this is followed by examining the functionality of the trio (organizational performance, strategic planning, financial planning); finally application of balanced scorecard as a mechanism for sustainable performance was explored and then the conclusion.

\section{Review Of Related Challenges And Attempts Of Nigerian Government Towards Effective Public Service}

It is a common knowledge that the public sector of every nation is germane to her national development. Through its ministries, departments and agencies, government puts in place policies, programmes and services that help galvanize development at all levels, engender economic progress and increase trust and connection between the managers of the state and the people (Imhonopi and Urim, 2013:79).

Related literatures reviewed conjecture that Nigeria public service has operated at suboptimal level since the country's independence. For instance, Adeyemo and Salami (2008) opined that the performance of public sector in Nigeria has been replete with varying contradictions (Adeyemo and Salami, 2008). This view was supported by Imhonopi and Urim (2013)who surmised that the Nigerian Public Sector has become an epitome of all that is corrupt, mediocre and fraudulent. Politics and politicization has systematically bastardized the very essence of the sector (Imhonopi and Urim, 2013). Consequently, morale is weak, remuneration is very poor, efficiency is no more, competence has been ditched and merit abandoned (Kagara, 2009). Perhaps, this accounts for why a larger proportion of the Nigeria national budget has been voted for the creation and sustenance of public enterprises (Adeyemo and Salami, 2008). Despite the best intentions from government, the Nigeria public sector still reels in politicization, merit sacrificed for quota-based recruitment and, or promotion, fraudulent staff claims, abuse of offices, kicks-backs (i.e. bribe for contract awards), absenteeism, lateness, lack of organizational commitment, idleness, insubordination, aggrandizement (Anyimetal, 2013).

The civil service in Nigeria for example, seems unable to cope with the prevailing ideological, political and economic changes as well as the management innovations; such that the institutional and capacity weakness of the civil service is considered one of the fundamental causes of socio-political upheavals and economic crisis (Chukwuemeka and Eme, 2011:17). Okpala (2012:114) reported that Nigeria lost several hundred billions of Naira over the last few decades due to flagrant abuse of procedures and lack of transparency and merit in the award of contracts in the public sector.

The enormity of challenges which characterized Nigerian public service within it's over fifty years of independence informs the barrage of reforms efforts by subsisting governments in Nigeria. Reforms are also meant, on the other hand, to tackle the challenges of public sector management in a sophisticated global environment driven by democratic ideals, modern technologies and market exigencies. This requires that the institutional scope, capacities and competencies of the public sector are broadened and the civil service restructured to meet present and future challenges (Olaopa, 2013)

Nigeria has attempted to answer reform questions through the setting up of reform commission, panels, study groups and so on; to analyze the management and function of government operations, and make recommendations that could orient the operations and functions towards the achievement of national objectives. Experience from history about the "what" and the "how" of reforms are useful in a nation's drive towards a desirable state in which the public sector will achieve an enviable performance in service delivery. Several shots have been taken by Nigerian government at administrative reforms since the second republic, these include:

a) Renewal programmes under Obasanjo regime- restructuring at the MDA level with a pilot phase involving ten ministries; a pay reform package; an Integrated Payroll and Personnel Information System (IPPIS) to 
establish a reliable database for the public service, facilitate manpower planning, eliminate record and payroll fraud, etc; a public expenditure management reform which consists of a medium-term planning and expenditure framework informed by medium-term sector strategies; the SERVICOM service delivery reform that would initiate a service delivery compact between the government and the Nigerian citizens; monetization of fringe benefits; pension reform; the National Economic Empowerment Development Strategy (NEEDS); and finally, an anti-corruption initiative that led to the establishment of Independent Corrupt Practices Commission (ICPC) and Economic and Financial Crime Commission (EFCC) to seal the loopholes in the civil service and penalize corrupt officials and citizens. The primary strength of the renewable programme is that it was a comprehensive programme as reflected in its being situated within an overall strategic plan of societal transformation aimed at addressing the crisis of state and governance in Nigeria.

b) Yaradua administrative reform consists of a commitment to four areas: to deepen democracy and the rule of law, build an economy driven primarily by the private sector, display zero tolerance for corruption in all its forms, and restructure and staff government to ensure efficiency and good governance. Yar'Adua also unveiled a Vision 20:2020 framework, similar to the Obasanjo's NEEDS, as a long-term framework for the economic transformation of Nigeria through the installation of a productivity paradigm in the national economy. Theseprogrammes automatically led to a commitment to the transformation of the civil service as the engine room for the implementation of the reform programme. This led to the development of a strategic document named the National Strategy for Public Service Reform (NSPSR) by the (Bureau of Public Service Reforms (BPSR).

c) The on-going Transformation Agenda of the Goodluck Jonathan administration is also largely founded on the basic premises and institutional framework existing since the Obasanjo reforms. It is equally a commitment to a professionalized civil service and a result-oriented management that would enable the government of Nigeria achieve its macroeconomic and social policies that would transform the Nigerian economy and its people.

In summary, existing literature reveals that focus in Nigeria public service has been on the financial and structural performances in terms of compliance of government agencies with guiding regulations and to a lesser extent on how the services has impacted on the general welfare of the Nigerian society as a long-term, sustained organizational improvement.

\section{Conceptual Framework}

To provide more insight into our subject of discourse, a closer look at some salient terms is instructive: 1) Organizational Performance, 2) Financial Planning, 3) Strategic Planning, and 4) Strategic Financial Planning.

\subsection{Organizational Performance}

Organizational performance has been defined as the ability of an organization to fulfill its mission through sound management, strong governance and a persistent rededication to achieving results. Effective organizations are mission-driven, adaptable, customer-focused, entrepreneurial, outcomes oriented and wellfocused on sustainable results. Organizational performance requires long-term commitment and investment, as well as stability and engagement of leadership.

Improved Organizational performance is a necessity to meet the demands of an increasingly complex and dynamic society. Knowledge and evidence-informed decision making are instrumental in increased organizational performance as both facilitate bridging of gaps and extending linkages.

Characteristics of a "high performance" public service:

a. Innovativeness:It has the encouragement and the ability to innovate.

b. Creativity:It is creative in its thinking, efficient in its processes, and has a culture of effective risk management.

c. Non-Partisanship:It demonstrates non-partisanship, excellence and pride in all facets of its work. It has the respect and support of the executive and the general public at large. It has active and transparent recruitment practices based on sound planning.

d. Result Oriented:It is structured to manage Human Resources effectively, enabling departments to deliver results for the citizenry. It plans, measures and is accountable for its performance. It engages rigorous performance management practices

e. Capacity Building:It has strong leadership and a commitment to developing talent. It has a clear regime for Human Resources governance and accountability 
f. Adaptability: It is very sensitive to changes in its environment with automated mechanisms for sustainable growth and development.

\subsection{What Is Strategic Planning?}

Strategic planning is an organization's process of defining its strategy, or direction, and making decisions on allocating its resources to pursue this strategy. It may also extend to control mechanisms for guiding the implementation of the strategy. Strategic planning is asystematicprocess of envisioning a desired future, and translating this vision into broadly defined goals or objectives and a sequence of steps towardsachieving them.

It is a continuous and systematic process where people make decisions about intended future outcomes, how these outcomes are to be accomplished and how success is to be measured and evaluated. Strategic planning will help the organization capitalize on their strengths, overcome their weaknesses, take advantage of opportunities and defend against threats to the organization.It demands a review and planning process that is undertaken to make thoughtful decisions about an organization's future in order to ensure its success.

Strategic planning involves clearly defining the organization's mission and an assessment of its current state and competitive landscape. It requires a well-thought out plan of how to properly allocate time, human capital and financial resources. By following a strategic planning process, an organization can improve business outcomes and avoid taking on unanticipated risks due to lack of foresight.

With a clear set vision by an organization, strategic planning deals with at least 1 of 3 key questions:

- "What do we do?"

- "For whom do we do it?"

- "How do we excel?"

Depending on the scope of an organization's plans, a strategic planning process can look forward one, five or ten years, or even more in some cases.Strategic planning is therefore, essentially the "why" that drives an operation. Once the "why"is known, the "how" can be figured out by outlining the requirements to get there. Further, all the strategic planning steps (defining firm's corporate purpose, scanning of business environment, identification of firm's strategic issues, strategy choice and setting up of implementation, evaluation and control systems) have been found to be positively related to company performance. Past studies have mainly focused on the direct relationship between strategic planning and performance and did not give attention to the specific steps that make up the strategic and financial planning process. The manner and extent to which each of the steps is practiced have implications on the expected performance.

\subsection{What is financial planning?}

Financial planning is one of the key elements of financial management. It is the task of determining "how" a business will achieve its strategic goals and objectives. Financial Planning is the process of estimating the resources required and determining its application. It is the process of framing objectives, policies, procedures, programmes and budgets regarding the financial activities of a concern. This ensures effective and adequate financial and investment policies. It is all about allocating finite resources such as- money, employees and equipment; over time, to reach the broad goals set out in strategic planning.

Management needs to ensure that enough funding is available at the right time to meet the needs of the organization. In the short-term, funding may be needed to invest in equipment and stocks and pay contractors/consultants. In the medium and long term, funding may be required for significant additions to the productive capacity of the organization.

Financial planning is more precise than strategic planning. Rather than dealing with setting idealized goals, financial planning is about manipulating real-world factors, specifically, money and human resources, to make the strategic plan tenable in a measurable period. The strategic plan may call for a lofty goal to happen in 10 years, but financial planning may dictate that it is more likely to happen in nine years, 11 years, or even 50 years (which would indicate a woefully inept strategic plan). You could say that strategic planning is about determining a destination and financial planning is about making sure the destination is reached. Financial planning has to be integrated with strategic planning early and thoroughly for it to work effectively and assuredly.

If strategic planning is the "what" and "why" of a company, financial planning is the "how" and "when".Therefore, financial planning ensures adequate funds, helps in ensuring a reasonable balance between outflow and inflow of funds so that stability and profitability is maintained, helps in facilitating growth and expansion programmes which aids enhanced performance of an organisation. 


\section{Nexus Of Strategic Financial Planning And Organizational Performance}

Strategic and financial planning (SFP) have proved to be an effective instrument in organizational quest for optimal performance. Unfortunately, in most organizations, especially in the public sector, strategic financial planning is implemented haphazardly. The following are some of the reasons why some public sector organizations do not engage in Strategic Financial Planning:

i. It is deemed to be time wasting which is associated with administrative bureaucracies inherent in strategic financial planning process.

ii. It requires enormous resources because the process of developing, implementing and feedback mechanism of strategic financial planning entails huge investment in human capital, physical equipment and financial assets.

iii. It requires a level of expertise, which is most often lacking in public services in developing countries.

iv. It enforces transparency and accountability and therefore exposes corrupt practices and ineptness in service delivery which corrupt governments are reluctant to pursue.

It is pertinent to note that any organization that wants to survive, grow and remain relevant in a constantly changing and competitive environment must respond and adjust to the evolving social, economic, political and environmental developments prevailing in the society. The environments of public organizations according to (Bryson, 2004) have become not only increasingly uncertain in recent years but is also more tightly interconnected; thus changes anywhere in the system reverberate unpredictably, and often chaotically and dangerously throughout the environment hence performance of an organization is a very relevant issue for continued existence. This increased uncertainty and interconnectedness requires a fivefold response from public organizations. First, these organizations must think strategically as never before. Second, they must translate their insights into effective strategies to cope with their changing circumstances. Third, they must develop the rationale necessary to lay the ground work for the adoption and implementation of their strategies. Fourth, they must build coalitions that are large enough and strong enough to adopt desirable strategies and protect themselves during implementation. And finally, they must build capacity for ongoing management of the strategic change.

In view of the many challenges that organizations are exposed to, it is imperative for them, both profit and nonprofit organizations, to anticipate challenges, identify their strengths to meet anticipated challenges and take control of available opportunities to obtain maximum productivity, that is, they must engage Strategic Financial Planning.

Richard A.Mittenthal, President of the TCC group in a publication in 2002, identified ten (10) keys to successful strategic and financial planning. These can be summarized as follows:

\section{A Clear And Comprehensive Grasp Of External Opportunities And Challenges:}

No organization exists in a static environment. Social, political and economic trends continually impact the demand for its offerings and services. Even as advances in technology present new opportunities, they also generate new expectations. Needs and community demographics are all subject to change. So too are methods for delivering programs and services. It is thus essential that a strategic plan reflect the external environment. Programs, services and operations should be reexamined and reshaped in the light of current realities and future projections.

\section{A realistic and comprehensive assessment of the organization's strengths and limitation:}

The bedrock of any successful strategic plan is a warts-and-all consideration of capabilities and strengths, weaknesses and limitations. Information, both objective and subjective, must be gathered from a wide array of sources, including staff and board members, clients, community leaders, funders and partner organizations among others.

\section{An inclusive approach:}

At one point or another, all important stakeholder groups should have a voice in the planning effort. At a minimum, that includes staff, current and incoming board members, clients, funders and partner organizations. To be sure all views will not be weighted equally, nor will every staff member be involved at every stage, it is possible to be inclusive without falling into the too-many-cooks trap. But a strategic plan should not become the exclusive responsibility of a small cadre of stakeholders. If the planning process is to succeed, it must incorporate the views of all the constituencies that will be affected by the plan or have role in its implementation. 


\section{An empowered planning committee:}

Strategic planning should be a participatory undertaking-but not an anarchic one. As a matter of practical necessity, the core work will generally be entrusted to a small planning committee with sufficient decision making authority to keep the project moving forward

\section{Involvement of senior leadership:}

Some executive directors and board members are inclined to take a hands-off approach when it comes to strategic planning, this must be avoided. They may simply lack the necessary time or interest to get involved. Or they may underestimate the significance of the task at hand and its potential impact on the organization.

\section{Sharing of responsibility by board and staff members:}

An effective plan takes multiple elements into account; the funding climate, the expectations of clients and other stakeholders, the competitive landscape and the exigencies of operations and programs. Neither board nor staff, acting on its own, has a full grasp of all those areas, hence the need to ensure that both are fully involved.

\section{Learning from best practices:}

Clearly, each organization has its own individualized mission, client base and operating culture. Thus, each must map a strategy, incorporating goals and action steps carefully customized to its needs. A plan that is appropriate in one setting may not necessarily be appropriate in another, no matter how similar the organizations. Nonetheless, it is possible to learn from successes, failures and mistakes of others.

\section{Clear priorities and an implementation plan:}

While missions and visions are essential to inspiring commitment to your organization, they may be seen as hollow unless accompanied by an organized description of activities needed to fulfill desired aims. Developing a workable strategic plan means dissecting the organization's objectives and strategies and setting them into logical sequence.

\section{Patience:}

For small and medium-size organizations, strategic planning often moves forward on a speedy timetable. But for larger organizations with many constituencies, the process may advance much less quickly. When an organization is making major changes and needs extensive buy-in, the process may not be perfectly linear. As information is gathered, sifted and analyzed, assumptions are re-thought, new ideas advanced and old ones revamped or discarded. It is important to keep things on course and maintain momentum, but rushing is counterproductive.

\section{A commitment to change:}

No matter how relevant its original mission, no organization can afford to shackle itself to the same goals, programs and operating methods year after year. As clients need, market conditions and funding criteria change, strategies need to be revisited regularly. Sometimes all that is needed is fine-tuning; other times a more fundamental rethinking of goals and opportunities may be required. If they are to remain viable and effective, organizations must be prepared to change extensively as conditions require.

\subsection{Objectives of Strategic and Financial Planning in Public Service:}

1. Focus: strategic and financial planning (sfp) enables identification and definition of goals, mission and vision.

2. Preemptive: strategic and financial planning provides basis for development of agile plans that support key initiatives as a process to effectively meet the goals, mission and vision.

3. Managerial: strategic and financial planning results in effective and efficient allocation and utilization of resources.

4. Performance consciousness: strategic and financial planning provides milestones for measurement of results (accountability) with target on improved performance.

5. Adaptability: strategic and financial planning provides better evidence for decision making, closer collaboration with the private and social sectors.

6. Result oriented: strategic and financial planning provides basis for greater engagement and empowerment of citizens, thoughtful investments in expertise and skill building, and growth and development driven. 


\subsection{Getting Better Performance through Strategic Financial Planning:}

i. Strategic Financial Planning will enable management, staff, and other stakeholders to reflect on the nature of the organization, the present and future needs of its customers, and possible changes in the environment including technology, social trends, and economic forces. It provides a systematic and objective assessment of the forces that will enable management to come to terms with unique strength of the organization.

ii. Strategic Financial Planning provides opportunity to involve the various levels of management in the process of planning. When different levels of management participate in strategy formulation, they get a clearer sense of where the organization wants to go. This to a very large extent facilitates the integration of employees and management to the goal and objectives of the organization thereby assuring higher performance.

iii. Strategic Financial Planning ensures that all the different units of the organization work together towards achieving the same objectives. Without a strategic plan, the organic units of the organization will slew off track. Strategic Financial Planning therefore provides an integrative mechanism for all organizational units to work together. Strategic Financial Planning therefore enables cybernetic controls especially in large complex organizations.

iv. Strategic Financial Planning provides an organization with a sense of direction (or road map) that enables it to clearly see where it is going and where the future will lead it. Without a sense of direction, an organization will spend its time reacting to problems thus, taking hasty and uninformed decisions that may be very costly.

v. Strategic Financial Planning provides a platform for the understanding of the expectations of stakeholders (such as, government, citizens, and employees) and the environmental forces that impact it (such as, political-legal, economic, socio-cultural, and technological) and how these affect the organization's growth (financial and otherwise) in the ever changing world.

vi. Strategic Financial Planningfosters, in management, the habit of periodically appraising the competitive position of their organizations. This compels management to be more proactive and conscious of the environment in which their organizations are operating.

vii. Strategic Financial Planning clearly defines the purpose of the organization and establishes realistic goals and objectives consistent with its mission in a defined time frame within the organization's capacity for implementation.

viii. Strategic Financial Planning enables management to communicate the organization's goals and objectives to the organization's constituents. There is the need to get employees informed or oriented about the mission, goal, and objectives of the organization in order to encourage them to work towards achieving the goal of the organization.

ix. Strategic Financial Planning develops a sense of ownership of the plan and therefore ensures that most effective use is made of the organization's resources by focusing the resources on the key priorities.

x. Strategic Financial Planning provide a base from which progress can be measured and establish a mechanism for informed changes when needed.

Strategic Financial Planning is known for improving communication, and participation within an organization, reducing conflicts related to the distribution of resources and promoting appropriate decisionmaking (Bryson, 2004).

\subsection{Attendant Challenges Of Strategic Financial Planning}

Various obstacles have been discussed by authors to alert public sector managers to the level of difficulty involved in operating programs in a result-oriented fashion. By recognizing the complexity and magnitude of business strategy implementation, managers can approach the challenge with realistic expectations. According to Kessler and Kelley (2000), there are significant challenges that could inhibit success unless dealt with aggressively and effectively. They include cultural issues, pessimism and skepticism, false support, passive resistance, preretirement lethargy, mismatches between strategy and structure, lack of funds, information technology constraints, communication gaps, and influence of unions and organized labor. Success in Strategic Financial Planning requires senior management sincerity, support, and involvement. Without these critical ingredients, ambitious goals are unlikely to be achieved. Furthermore, Beer and Russell (2000), presented that the six silent killers of strategy implementation are: top-down or complacent upper management, unclear strategy and conflicting priorities, ineffective senior management team, poor vertical communication, poor coordination across the enterprise and inadequate middle-manager and supervisor management skills. 


\section{Contemporary Performance Measurement Contraptions}

To address the inherent weaknesses of the traditional performance measurement framework, management scientists and scholars sought to development plausible performance frameworks that would engender healthy growth and development of organizations. Neely et al. (2000), Tangen (2004) and Neely, Kennerley and Adams (2007) presented six contemporary performance measurement frameworks:

1. The Performance Measurement Matrix

2. The Results and Determinants framework

3. The input-process-output-outcome framework

4. The SMART (strategic measurement and reporting technique)Pyramid

5. The Performance Prism

6. The Balanced Scorecard (BSC)

The common traits of these performance measures are that: they combine financial and non-financial elements of the business as well as external and internal factors in measurement of performance (Neely et al. (2000), Fitzgerald, Johnston, Brignall, Silvestro and Voss's (1991), Brown (1996), Lynch and Cross (1991), Tangen (2004), and Kaplan and Norton (1993)).

\section{Leveraging On Balanced Scorecard As A Panacea}

Contemporary strategic management literature suggests that there should be a strong linkage between strategic plans and performance measures. Kaplan and Norton's (1992) balanced scorecard and Fitzgerald etal (1991) results and determinants framework can provide this linkage. As a way forward, Nigeria government can leverage on balanced scorecard to consolidate on gains of its strategic efforts over the years.

The balanced scorecard is a strategic planning and management system that is used extensively in business and industry, government, and nonprofit organizations worldwide to align business activities to the vision and strategy of the organization, improve internal and external communications, and monitor organization performance against strategic goals. It was originated by Drs. Robert Kaplan (Harvard Business School) and David Norton as a performance measurement framework that added strategic non-financial performance measures to traditional financial metrics to give managers and executives a more 'balanced' view of organizational performance.

The balanced scorecard has evolved from its early use as a simple performance measurement framework to a full strategic planning and management system. The "new" balanced scorecard transforms an organization's strategic plan from an attractive but passive document into the "marching orders" for the organization on a daily basis. It provides a framework that not only provides performance measurements, but helps planners identify what should be done and measured. It enables executives to truly execute their strategies (Kaplan and Norton, 1996). It is a management system (not only a measurement system) that enables organizations to clarify their vision and strategy and translate them into action. It provides feedback around both the internal business processes and external outcomes in order to continuously improve strategic performance and results. When fully deployed, the balanced scorecard transforms strategic planning from an academic exercise into the nerve center of an enterprise (Kaplan and Norton, 1996).

The balanced scorecard retains traditional financial measures. But financial measures tell the story of past events, an adequate story for industrial age companies for which investments in long-term capabilities and customer relationships were not critical for success. These financial measures are inadequate, however, for guiding and evaluating the journey that information age companies must make to create future value through investment in customers, suppliers, employees, processes, technology, and innovation. Therefore, in addition to focus on traditional financial performance, the balanced scorecard takes into account non-financial aspects of corporate performance, such as customer satisfaction and business processes, to create a complete picture of how the company is likely to perform in the future. For example, reducing the level of customer service may boost current earnings, but the balanced scorecard approach would also take into account potential loss of future earnings due to poor customer satisfaction. The balanced scorecard approach therefore allows managers to more easily identify the aspects of the business they need to monitor more closely, and highlight the areas that need improvement. By taking a holistic approach, the balanced scorecard system also lets managers monitor what company-wide objectives have been met, and what is needed to achieve strategic goals. In balanced scorecard, managers waste less time monitoring and have an increased understanding of the steps needed to achieve their goals.

So, what is the Balanced Scorecard? It is a management system that enables an organization to set, track, and achieve its key business strategies and objectives. After the business strategies are developed, they are deployed and tracked through the Four Legs of the Balanced Scorecard. These four legs comprise four distinct business perspectives: The Customer Leg (market or community analysis), the Financial Leg (financial 
management), the Internal Business Process Leg (business structure and process development), and the Knowledge, Education, and Growth Leg (human capital development or innovativeness). These four legs of the Balanced Scorecard are necessary for contemporary managers to be able to plan, implement, and achieve their business strategies.

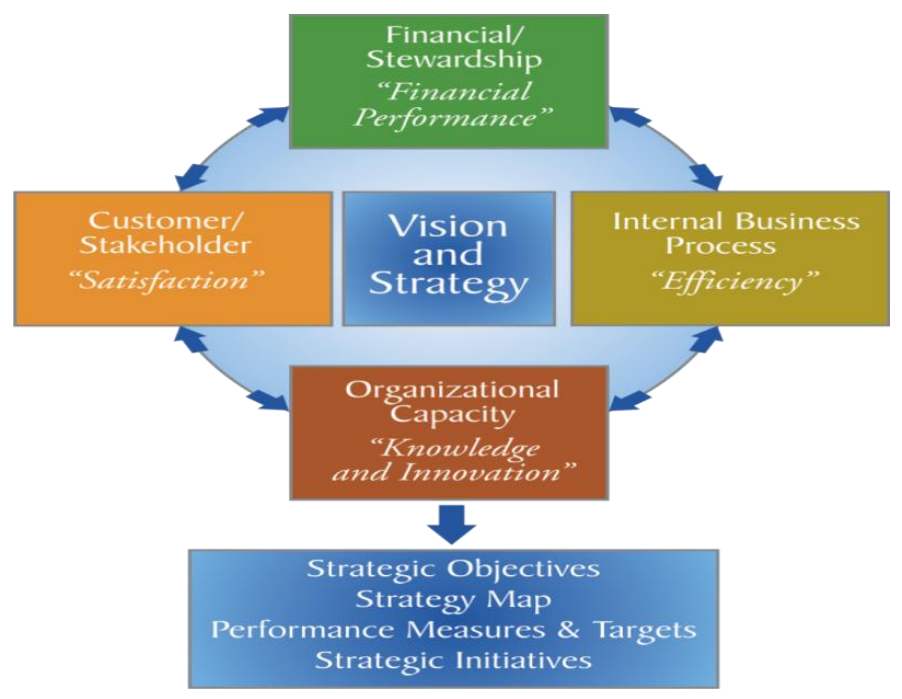

Adapted from Robert S. Kaplan and David P. Norton, "Using the Balanced Scorecard as a Strategic Management System,” Harvard Business Review (January-February 1996): 76.

These four legs have to be measured, analyzed, and improved together, continuously, in order for an organization to succeed. Balanced scorecard is therefore an instrument which intertwines strategic and financial planning mechanisms into effective organizational performance.

\section{Conclusion And Recommendation:}

In the government sector, given that objectives are often stated in non-financial terms, non-financial performance measures are needed as conventional financial reporting will not fully capture performance (Guthrie and English, 1997). Companies and forward-looking governments around the world have come to recognize the importance of the balanced scorecard and have embraced its use as a strategic financial management instrument. Tailoring Nigerian strategic financial planning efforts in semblance of balanced scorecard would eliminate haphazard and incoherent tendencies characterizing public services offered by various government agencies and entrench goal congruency towards optimal public sector performance in near future. The balanced scorecard would assist Nigerian government to develop meaningful performance measures and facilitate performance management, financial stewardship and accountability, with satisfaction of the citizens as the ultimate goal.

It is recommended that the Nigerian government should leverage on the framework of balanced scorecard in its future development plans to enable an all-inclusive but simplified strategic development structures which will entrench consistent measurable results and tangible economic growth.

\section{Bibliography}

[1]. Abdullahi A Malgwi, Angus O. Unegbu, Budget in Nigerian Public Sector: Need for Balanced Scorecard Perspective, International Journal of Finance and Accounting, Vol. 1 No. 2, 2012, pp. 1-6. doi: 10.5923/j.ijfa.20120102.01.

[2]. Adeyemo, D.O. and Salami A. (2008), 'A review of privatization and public enterprises reform in Nigeria', Contemporary Management Research, 4(4), 401-418, December 2008.

[3]. AnyimF.C.,Ufodiama N.M. and OlusanyaO.A. (2013), Ethics in Nigeria Public Sector: The HRPractioners Perspective, European Journal of Business and Social Sciences, Vol. 2, No.8, pp 132-143, November 2013. 132 - 143 URL: http://www.ejbss.com/recent.aspx

[4]. Bititci, U.S. Mendibil, K. Martinez V. and Albores P.(1997), "Measuring and Managing Performance in Extended Enterprises" International Journal of Operations and Production Management.Vol. 25, (4), pp 333-353.

[5]. Bryson J.M. (2004), Strategic Planning for Public and Nonprofit Organizations: A Guide to Strengthening and Sustaining Organizational Achievement. Wiley

[6]. Chukwuemeka, E.andEme, O.I. (2011), 'Refocusing the Federal Civil Service: The role of the Head of Service', Arabian Journal of Business and Management Review (OMAN Chapter) 1(5), 17-31; December.

[7]. Elzinga, T., Albronda, B. \&Kluijtmans, F. (2009). Behavioral factors influencing performance management systems' use. International Journal of Productivity and Performance Management , 58 (6), 508-522. doi: 10.1108/1741044000910977064

[8]. Fitzgerald, L., Johnston, R., Brignall, T. J., Sivestro, R. and Voss, C. (1991), Performance Measurement in Service Businesses, London, CIMA. 
[9]. Guthrie, J. and English, L. (1997), Performance information and program evaluation in the Australian public sector, International Journal of Public Sector Management, 10(3).

[10]. Imhonopi, D. and Urim, U.M. (2013), 'Leadership crisis and corruption in the Nigerian public sector: An albatross of national development', The African Symposium, 13(1), 78-87, June

[11]. KagaraH.S. (2009), 'Oronsaye's Civil Service reform: Another Option', Retrieved, September 05, 2013 from http://economicconfidential.net/new/features/4

[12]. Kaplan, R. S. and Norton, D. P. (1992), "The balanced scorecard: Measures that drive performance", Harvard Business Review, Jan -Feb, 71-79

[13]. Kaplan, R.S. \& Norton, D.P. (1993).Putting the balanced scorecard to work. Harvard Business Review , 71 (September-October), 134-147. AN 9312031654.

[14]. Kaplan, R. S. and Norton, D. P. (1996), "Using the balanced scorecard as a strategic management system", Harvard Business Review, Jan -Feb, 75-85.

[15]. Mittenthal, R.A. (2002), Ten Keys to Successful Strategic Planning for Nonprofit and Foundation Leaders. Ossey-Bass Publishers.

[16]. Neely, A., Mills, J., Platts, K., Richards, H., Gregory, M., Bourne, M. \&Kennerley, M. (2000). Performance measurement system design: developing and testing a process- based approach. International Journal of Operations \& Production Management , 20 (10), 1119-1145.

[17]. OkpalaK.E. (2012), 'Fiscal accountability dilemma in Nigeria public sector: A warning model for economic retrogression', Research Journal of Finance and Accounting 3(6), 113 - 131.

[18]. Olaopa, T. (2013), "Beyond Public Service Reform: The Imperative of a New National Productivity Paradigm". ThisDay Newspaper (Lagos)(February) pp.95.

[19]. Palmer, A. J., 1993, 'Performance measurement in local government', Public Money and Management, Oct-Dec; vol 13 (4), pp.3136. UK.

[20]. Tangen, S. (2004). Performance measurement: from philosophy to practice. International Journal of Productivity and Performance Management, 53 (8), 726-737. doi: 10.1108/17410400410569134. 